\title{
Old Age Prejudice in Mexican University Students: Comparisons by Gender
}

\author{
Dr. Perla Jannet Jurado Garcia, \\ Dr. Susana Ivonne Aguirre Vásquez, \\ M.C. Edgar Francisco Ordonez Bencomo, \\ Dr. Humberto Blanco Vega, \\ Dr. Maria del Carmen Zueck Enriquez, \\ Dr. Jesus Enrique Peinado Perez, \\ Dr. Jose Rene Blanco Ornelas, \\ Facultad de Ciencias de la Cultura Física \\ Universidad Autónoma de Chihuahua
}

Doi:10.19044/esj.2020.v16n11p73 ～URL:http://dx.doi.org/10.19044/esj.2020.v16n11p73

\begin{abstract}
The goal of the present research was to compare the profiles of old age prejudice in male and female students from the area of physical activity. The study was conducted from January to October 2016. Participants were recruited from different semesters of the Physical Education and Human Motricity bachelor's degrees offered at the Faculty of Physical Culture Sciences of the Autonomous University of Chihuahua, Mexico. The sample was obtained through convenience sampling, and included 1652 participants; 828 women and 824 men, mean age was $20.51 \pm 1.83$ years $20.90 \pm 2.03$ years respectively. The approach of the study was quantitative with a descriptive survey-like design. All participants completed the Questionnaire on Negative Stereotypes towards Old Age. Results from the Multivariate Analyses of Variance, and the follow-up Univariate Analyses of Variance, show that men report greater levels of prejudice towards old age on the sociomotivational $(\mathrm{F}=31.657, \mathrm{p}<.001)$ and character-personality $(\mathrm{F}=15.789$, $\mathrm{p}<.001$ ) factors. No differences were found on the health factor (i.e., mental and physical). These results suggest that when designing any type of intervention in which the purpose is to improve the perception of young people towards the elderly, the variable gender should be considered. Future research should replicate these findings in larger samples.
\end{abstract}

Keywords: Prejudice, gender differences, higher education, old age, student beliefs 


\section{Introduction}

When speaking about old age, a vast variation of the concept must be considered. There is no clear distinction between the terms used in expressions such as old, long-lived or senescence, given that they are used as synonyms depending also on the place and its customs. However, the concept of old age has certain negative connotations, related to disability and deterioration. This supports the myth that "being old is being sick", as old age tends to be associated with a greater susceptibility to illness, deterioration of bodily functions and death (Brunton \& Scott, 2015; Guadarrama, Veytia, Arzate, Hernández, \& Albiter, 2017).

Thence, old age and aging are topics plagued with myths, prejudices and stereotypes. On occasions, stereotypes are positive and negative, although in general, they tend to be negative. When they are positive, stereotypes associate old age with wisdom, experience, and prudence. When stereotypes are negative, old age is related with poor health, low productivity, dependence, solitude, and bad humor (Arias, Lirio, Herranz, Alonso, \& Portal, 2018). It is worth mentioning that exposure to negative stereotypes combined with discrimination affects the older adults' health and physical and mental wellbeing, and become a source of psychological, cognitive, and physiological stress. Thus, internalized negative stereotypes can lead to self-fulfilling prophecies and contribute to disability, dependency and perception of poor health in the elderly (Allen, 2016; Barranquero \& Ausín, 2019).

Stereotypes reflect the strong impact of social and cultural influences over individuals' attitudes, beliefs and expectations with regards to the aging process. Such stereotypes tend to function as schemes based more on preconceived ideas than on reality. Such schemes can influence behaviors in people who sustain them, favoring discriminatory attitudes and practices in different areas of their life (Menéndez, Cuevas-Toroa, Pérez-Padilla, \& Lara, 2016; Portela, 2016).

Discriminatory attitudes can be measured in relation to stereotypes and prejudices against the elderly because of their advanced age. This phenomenon is defined as ageism and it implies the attribution of diverse characteristics to a person only because he or she is old. Such behaviors are internalized, operate on a subconscious level and gain great importance along a person's lifespan. Due to this, the aging process is perceived and experienced with greater levels of anxiety, resulting in an increase of discriminatory attitudes against the elderly and giving way to prejudices, discrimination, and ageist behaviors (Bousfield \& Hutchison, 2010; Diehl et al., 2014; Kornadt \& Rothermund, 2011; Levy, 2009).

Research on the topic has analyzed the relation between various sociodemographic characteristics such as sex, age, level of education, socioeconomic status, and indicators such as coexistence with elderly people. 
Ručević, Humer, and Toter (2015) conducted a study with participants between the ages of 18 and 25 and older adults between the ages of 60 and 75, the researchers observed that both groups possessed slightly positive attitudes towards older adults. In addition, positive expectations towards a successful aging process were found to be greater in young adults. Ozdemir (2016) determined that students' increase in age and time attending older adults in clinical practice are related to positive attitudes towards aging.

In research that has examined students' attitudes towards older adults as a function of coexistence, findings show that students who did no coexist with some older adult presented more negative stereotypes (Duran-Badillo et al., 2016). On the contrary, Rello, López, and Muñoz (2018) found that people whose frequency of contact with older adults was daily, various days a week or at least once a week showed less stereotypes towards aging than those people with occasional contact.

On the other hand, both the quality and greater duration of the contact with older adults have been associated with more positive attitudes towards this group (Drury, Hutchison, \& Abrams, 2016). However, a study conducted by Kusumastuti et al. (2017) reported that after intergroup contact with older adults, scores were particularly low on behavior towards and pleasantness of interaction with older adults. Results indicated that prior to contact with older adults, participants already had a negative image which tended to worsen after intergroup contact during a care internship.

With regards to socio-economic status, authors such as León, CorreaBeltrán, and Giacaman (2015) report that people with lower middle and low socio-economic status show more positive attitudes towards aging than participants from high and medium high socio-economic status. In addition, according to Alquwez, Cruz, Almazan, Alamri, and Mesde (2018) students who live in rural areas show more positive attitudes towards aging than students who live in urban areas.

These findings show that age stereotypes are complex and multidimensional, that they vary according to the domain of life, and that their activation is highly specific according to the situation (Casper, Rothermund, \& Wentura, 2011; Kornadt \& Rothermund, 2011). In addition, negative attitudes towards aging frequently based on the association between old age and laziness, inactivity, poverty, and illness (Cerquera, Meléndez, \& Villabona, 2012) can be a primary stress factor that contributes to the deterioration of health and well-being in older adults (Barranquero \& Ausín, 2019). In this sense, the study of prejudices towards older adults in male and female Mexican university students using the Questionnaire on Negative Stereotypes towards Old Age Mena, Sánchez-Palacios y Trianes (2005), is especially relevant. 
The goal of the present study was to determine the differences and similarities between male and female Mexican university students with regards to prejudices towards older adults. Consequently, this applied research, intends to contribute information that translates into an educational practice of greater quality in the context of attention to diversity. The goal being to provide the future health professionals with an integral education, that allows for the development of adequate strategies for proper attention to older adults, and a decrease in discriminatory attitudes and behaviors towards this age group.

\section{Materials and methods \\ Participants}

The study was conducted during the months of January to October 2016 including university students from the city of Chihuahua, Mexico. The sample was obtained by convenience sampling. We tried to obtain a sample that included students from the different semesters of the Physical Education and Human Motricity Bachelor's Degrees offered at the Faculty of Physical Culture Sciences at the Autonomous University of Chihuahua.

The total sample was composed of 1652 participants 828 (50.1\%) female and $824(49.9 \%)$ male. Participants' age ranged between 18 and 28 years with $\mathrm{M}=20.51 \pm 1.83$ years for women and $\mathrm{M}=20.90 \pm 2.03$ years for men.

For the inclusion criteria, participants had to be regular students at the Faculty of Physical Culture Sciences, in addition they had to express their compliance to participate in the study by reading and agreeing to the informed consent (completed through an electronic survey). Students who were informed and did not agree to the informed consent were excluded from the study.

\section{Instrument}

The Questionnaire on Negative Stereotypes towards Old Age (CENVE for its initials in Spanish) by Mena, Sánchez-Palacios, and Trianes (2005) is a 15-item Likert type survey designed to assess the prejudice towards old age. Participants responded on a scale of 1 to $4(1=$ strongly disagree, $2=$ somewhat disagree, $3=$ somewhat agree and $4=$ strongly agree) according to their degree of agreement with each of the proposed aspects.

The items of the questionnaire are grouped into three factors: Health, degree of negative stereotype related to physical and mental health (items 1, 4, 7, 10 and 13); Motivational-social, degree of negative stereotype referred to aspects of motivation and interpersonal relationships (items 2, 5, 8, 11 and 14); Character-personality, degree of stereotype referred to the characterpersonality (items 3, 6, 9, 12 and 15). 
For the present study, the following adaptations were made: first, whereas in the original scale four response options are scored, in the version used in the present research, the participant chooses from eleven possible options on a scale of 0 to 10 . This adaptation is justified in relation to the participants, they are used to the scale of $0-10(0=$ Completely Disagree, 1 to $3=$ Disagree, 4 to $6=$ Sometimes false sometimes true, 7 to $9=$ Agree and 10 = Completely Agree), since they have been evaluated this way by the educational system of our country (Mexico). Viciana, Cervelló, and Ramírez (2007) report a similar change in the validation of a scale with Spanish population. The second adaptation consisted in elaborating a computerized version of the questionnaire using the software designed by Blanco and collaborators (2013). This last adaptation was made in order to facilitate the application procedure and the tabulation of results, thus increasing the speed and efficiency of these processes.

\section{Design}

Regarding the design of the study, we used a quantitative approach with a descriptive cross-sectional survey like design (Hernández, Fernández, \& Baptista, 2014). The independent variable was gender and the dependent variables were the mean scores obtained on each of the three factors or subscales of the Questionnaire on Negative Stereotypes towards Old Age (CENVE for its initials in Spanish).

\section{Procedure}

The students of the two degrees offered at the Faculty of Physical Culture Sciences of the Autonomous University of Chihuahua (FCCF) were invited to participate in the study.

Those who agreed to participate signed the corresponding consent form. The instrument described above was then completed on a personal computer (manager module of the instrument of the typical execution scales editor), in the computer laboratories at the Faculty of Physical Culture Sciences, in a single session that lasted approximately 30 minutes.

At the beginning of each session, a brief introduction was made on the importance of the research and how to access the instrument. Participants were asked for the utmost sincerity and were guaranteed the confidentiality of the obtained data. Instructions on how to respond were shown on the first screens, before the first item of the instrument. At the end of the session, students were thanked for their participation.

Once the instrument was completed, the results were collected using the results generator module of the scale editor version 2.0 (Blanco et al., 2013). 


\section{Data analyses}

Descriptive statistics were calculated (means and standard deviations) for all variables. Subsequently, after verifying that the data met the assumptions of parametric statistical analysis, a multiple analysis of variance (MANOVA) followed by univariate analyses of variance (ANOVA) were conducted to examine the differences between women and men in terms of their negative stereotypes towards old age on each of the questionnaire subscales. The size of the effect was estimated by the eta-square ( $\eta 2)$. All statistical analyses were performed with SPSS software version 20.0 for Windows. The level of statistical significance was set at $\mathrm{p}=.05$.

\section{Results}

Table 1 shows mean values and standard deviations of the scores in each of the questionnaire subscales of negative stereotypes towards old age, as well as the results of MANOVA and subsequent ANOVAs. The MANOVA results showed statistically significant global differences by gender in the negative stereotype scores for old age (Wilks $\lambda=.974, \mathrm{p}<.001 ; \eta 2=.026$ ). The ANOVAs indicated that, in comparison to female students, men showed higher scores in the Social-Motivational $(F=31,657, p<.001 ; \eta 2=.019)$ and Character-Personality subscales $(\mathrm{F}=15.789, \mathrm{p}<.001 ; \eta 2=.009)$, no differences were found on the Health subscale.

Table 1: Results from the MANOVA and ANOVAs for the differences on negative stereotypes towards old age by gender

\begin{tabular}{|l|l|l|l|l|l|}
\hline & $\begin{array}{l}\text { Women } \\
(n=828)\end{array}$ & $\begin{array}{l}\text { Men } \\
(n=824)\end{array}$ & $F$ & $p$ & $\eta^{2}$ \\
\hline & & & 14.662 & $<.001$ & .026 \\
\hline Health & $5.86(1.49)$ & $5.95(1.52)$ & 1.399 & $>.05$ & .001 \\
\hline $\begin{array}{l}\text { Social- } \\
\text { Motivational }\end{array}$ & $5.08(1.52)$ & $5.51(1.58)$ & 31.657 & $<.001$ & .019 \\
\hline $\begin{array}{l}\text { Character- } \\
\text { Personality }\end{array}$ & $5.73(1.46)$ & $6.02(1.48)$ & 15.789 & $<.001$ & .009 \\
\hline
\end{tabular}

Note. Descriptive statistics are presented as mean (standard deviation).

\section{Discussion}

Results show that male students, in comparison to women, show greater prejudices towards old age in terms of motivation, interpersonal relationships, character and personality towards older adults. Results are in general consistent with similar studies by Arias et al., (2018) and Pabón, Flórez, \& Sanabria, (2019) who report greater negative stereotypes on motivation, character and personality. With regards to gender, Smith et al. (2017) report that male students maintained more negative stereotypes about older people despite having lived more frequently with an older adult. Various factors such 
as personal and/or professional experiences and the more caring nature of women may explain that it was women who showed less negative stereotypes.

In contrast to these studies, Menéndez, Cuevas-Toro, Pérez-Padilla, \& Lorence, 2016 and Nunes, Menéndez, Martins, \& Martins, 2018, report no significant differences by gender. In the present study, no significant differences were found in terms of physical and mental health. This is consistent with Gutiérrez and Mayordomo (2019), and contrary to DuranBadillo et al., (2016) and Portela, (2016) who sustain that the most stereotyped factor is the health dimension.

\section{Conclusion}

From the obtained results we conclude that:

1. The results show that, in general, men compared to women report higher negative prejudices towards old age, specifically in relation to motivation, interpersonal relationships, character and personality.

2. The encountered differences between male and female university students with respect to prejudices towards old age suggest the need to increase the efforts in changing young students' perception with regards to character, personality and health factors given that the attitudes of the future professionals could influence the quality of attention towards older adults.

However, it is important to develop more research as the topic goes far beyond the scope of this study. The importance of conducting a greater amount of research in our country is also underlined. Finally, at least two limitations are present in this work. First, participants were all Mexican university students, which poses a threat to the possibility of generalizing these results. Enlarging the sample (including young adults who are not students) is an area of opportunity for the future. The second limitation comes from the measurement instrument which is based on self-report and thus may contain bias derived from social desirability.

\section{References:}

1. Alquwez, N., Cruz, J. P., Almazan, J. U., Alamri, M. S., \& Mesde, J. J. (2018). The Arabic version of the Kogan Attitudes toward Older People Scale among Saudi nursing students: a psychometric analysis. Annals of Saudi medicine, 38(6), 399-407. doi: 10.5144/02564947.2018.399

2. Allen, J. O. (2016). Ageism as a Risk Factor for Chronic Disease. The Gerontologist, 56(4), 610-614. doi: 10.1093/geront/gnu158

3. Arias, E., Lirio, J., Herranz, I., Alonso, D., \& Portal, E. (2018). Ageism at university: A comparative analysis of young and older adult 
students. Educational Gerontology, 44(11), 679-692. doi: 10.1080/03601277.2018.1526456

4. Barranquero, R., \& Ausín, B. (2019). Impacto de los estereotipos negativos sobre la vejez en la salud mental y física de las personas mayores. Psicogeriatría, 9(1), 41-47.

5. Blanco, H., Ornelas, M., Tristán, J. L., Cocca, A., Mayorga-Vega, D., López-Walle, J., \& Viciana, J. (2013). Editor for creating and applying computerise surveys. Procedia Social and Behavioral Sciences, 106, 935-940. doi:http://dx.doi.org/10.1016/j.sbspro.2013.12.105

6. Bousfield, C., \& Hutchison, P. (2010). Contact, anxiety, and young people's attitudes and behavioral intentions towards the elderly. Educational Gerontology, 36(6), 451-466.

7. Brunton, R., \& Scott, G. (2015). Do We Fear Ageing? A multidimensional approach to ageing anxiety educational gerontology. Educational Gerontology, 41(11), 786-799.

8. Casper, C., Rothermund, K., \& Wentura, D. (2011). The activation of specific facets of age stereotypes depends on individuating information. Social Cognition, 29(4), 393-414.

9. Cerquera, A. M., Meléndez, C., \& Villabona, C. B. (2012). Identificación de los estereotipos sobre envejecimiento femenino, presentes en un grupo de mujeres jóvenes. Pensamiento Psicológico, 10(1), 77-88.

10. Diehl, M., Wahl, H.-W., Barrett, A., Brothers, A., Miche, M., Montepare, J., Westerhof, G.J.,Wurm, S. (2014). Awareness of aging: Theoretical considerations on an emerging concept. Developmental Review, 34(2), 93-113. doi:/10.1016/j.dr.2014.01.001

11. Drury, L., Hutchison, P., \& Abrams, D. (2016). Direct and extended intergenerational contact and young people's attitudes towards older adults. The British journal of social psychology, 55(3), 522-543. doi: 10.1111/bjso.12146

12. Duran-Badillo, T., Miranda-Posadas, C., Cruz-Barrera, L. G., Martínez-Aguilar, M. d. 1. L., Gutiérrez-Sánchez, G., \& AguilarHernández, R. M. (2016). Estereotipos negativos sobre la vejez en estudiantes universitarios de enfermería. Rev Enferm Inst Mex Seguro Soc, 24(3), 205-209.

13. Guadarrama, R., Veytia, M., Arzate, G., Hernández, J. C., \& Albiter, J. (2017). Actitud hacia la vejez: Estudio comparativo en mujeres mexiquenses. Psicología Iberoamericana, 25(2), 44-52.

14. Gutiérrez, M., \& Mayordomo, T. (2019). Age discrimination: a comparative study among university students. Acta Colombiana de Psicología, 22(2), 53-61. doi: 10.14718/ACP.2019.22.2.4 
15. Hernández, R., Fernández, C., \& Baptista, P. (2014). Metodología de la investigación. México: McGraw- Hill.

16. Kornadt, A., \& Rothermund, K. (2011). Contexts of aging: assessing evaluative age stereotypes in different life domains. The Journals of Gerontology Series B: Psychological Sciences and Social Sciences, 66(5), 547-556.

17. Kusumastuti, S., Van Fenema, E., Polman-van Stratum, E. C., Achterberg, W., Lindenberg, J., \& Westendorp, R. G. (2017). When Contact Is Not Enough: Affecting First Year Medical Students' Image towards Older Persons. PloS one, 12(1), e0169977. doi: 10.1371/journal.pone.0169977

18. León, S., Correa-Beltrán, G., \& Giacaman, R. (2015). Negative ageing stereotypes in students and faculty members from three health science schools. Gerodontology, 32(2), 141-148. doi: 10.1111/ger.12065

19. Levy, B. (2009). Stereotype embodiment a psychosocial approach to aging. Current Directions in Psychological Science, 18(6), 332-336.

20. Mena, M. J. B., Sánchez-Palacios, C., \& Trianes, M. V. (2005). Cuestionario de evaluación de estereotipos negativos hacia la vejez. Revista multidisciplinar de gerontología, 15(4), 212-220.

21. Menéndez, S., Cuevas-Toro, A. M., Pérez-Padilla, J., \& Lorence, B. (2016). Evaluación de los estereotipos negativos hacia la vejez en jóvenes y adultos. [Assessment of negative stereotypes about old age in young people and adults]. Revista Española de Geriatría y Gerontología, 51(6), 323-328. doi: 10.1016/j.regg.2015.12.003

22. Menéndez, S., Cuevas-Toroa, A. M., Pérez-Padilla, J., \& Lara, B. (2016). Evaluación de los estereotipos negativos hacia la vejez en jóvenes y adultos. Revista Española de Geriatrı y Gerontologia, 1-6.

23. Nunes, C., Menéndez, S., Martins, C., \& Martins, H. (2018). Psychometric properties of the Negative Stereotypes Towards Aging Questionnaire (CENVE) among a sample of Portuguese adults. Psicologia: Reflexão e Crítica, 31(3). doi: 10.1186/s41155-018-00850

24. Özdemir, Ö. (2016). Attitudes of Turkish Nursing Students Related to Ageism. Journal of Nursing Research, 24(3), 211-216. doi: 10.1097/jnr.0000000000000131

25. Pabón, D. K., Flórez, A. L., \& Sanabria, L. M. (2019). Estereotipos sobre la población adulta mayor en tres grupos etarios de cuidadores de personas mayores dependientes. Actualidades en Psicología, 33(127), 63-80. doi: 10.15517/ap.v33i127.34291.

26. Portela, A. (2016). Estereotipos negativos sobre la vejez en estudiantes de Terapia Ocupacional. Revista Argentina de Terapia Ocupacional, 2(1), 3-13. 
27. Rello, C. F., López, M. D., \& Muñoz, R. M. (2018). Estereotipos sobre la edad y el envejecimiento en estudiantes y profesionales de Ciencias de la Salud. Revista Prisma Social, 21, 108-122.

28. Ručević, S., Humer, J., \& Toter, K. (2015). Usporedba stavova i stereotipa o starijim osobama te očekivanja vezanih uz starenje: Uloga dobi i kontakta. Ljetopis Socijalnog Rada/Annual of Social Work, 22(2), 223-240. doi: 10.3935/ljsr.v22i2.66

29. Smith, M., Bergeron, C. D., Cowart, C., Ahn, S., Towne, S. D., Ory, M. G., Chaney, J. D. (2017). Factors associated with ageist attitudes among college students. Geriatrics \& gerontology international, 17(10), 1698-1706. doi: 10.1111/ggi.12894.

30. Viciana, J., Cervelló, E. M., \& Ramírez, J. (2007). Effects of manipulating positive and negative feedback on goal orientation, perceived motivational climate, satisfaction, task choice, perception of ability, and attitude to physical education lessons. Perceptual and motor skills, 105(1), 67-82 